See Article page 338.

\section{Commentary: Anastomoses for esophagectomy: Surgeons may always know which is the better option for themselves}

\author{
Bin Li, MD, and Haiquan Chen, MD
}

Surgery is a crucial part of the treatment of esophageal cancer as upfront esophagectomy for early-stage cancers and esophagectomy combined with chemotherapy and/or radiotherapy for cancers at locally advanced stage. However, there is still no consensus on the optimal procedure for esophagectomy, particularly for the anastomosis, which is an important issue of surgery.

Although postoperative morbidity has declined with improvements in surgical techniques, anastomotic leakage remains a common complication following esophagectomy and an important cause of hospital mortality after surgery. Many factors contribute to the occurrence of anastomotic leakage, the 2 most important factors of which seem to be tension and blood supply of the gastric tube. Based on the tumor location and surgeon's preference, anastomosis can be performed in the neck or in the chest.

In the literature, cervical anastomotic leakages are more common than thoracic leakages, with an incidence of more than $10 \%{ }^{1}$ Efforts were made to reduce the incidence of cervical anastomotic leakage, including using different anastomotic techniques between hand-sewn and stapled technique, different reconstructions routes between retrosternal and prevertebral routes, and different shaping of the gastric tube. Moreover, hand-sewn anastomosis

\footnotetext{
From the Department of Thoracic Surgery, Fudan University Shanghai Cancer Center, and Institute of Thoracic Oncology, Fudan University, Shanghai, China. Disclosures: The authors reported no conflicts of interest.

The Journal policy requires editors and reviewers to disclose conflicts of interest and to decline handling or reviewing manuscripts for which they may have a conflict of interest. The editors and reviewers of this article have no conflicts of interest.

Received for publication Aug 4, 2021; revisions received Aug 4, 2021; accepted for publication Aug 6, 2021; available ahead of print Aug 26, 2021.

Address for reprints: Haiquan Chen, MD, Department of Thoracic Surgery, Fudan University Shanghai Cancer Center, and Institute of Thoracic Oncology, Fudan University, 270 Dong'an Rd, Shanghai 20032, China (E-mail: hqchen1@yahoo. com).

JTCVS Open 2021;7:353-4

2666-2736

Copyright (C) 2021 The Author(s). Published by Elsevier Inc. on behalf of The American Association for Thoracic Surgery. This is an open access article under the CC BY-NC-ND license (http://creativecommons.org/licenses/by-nc-nd/4.0/).

https://doi.org/10.1016/j.xjon.2021.08.008
}

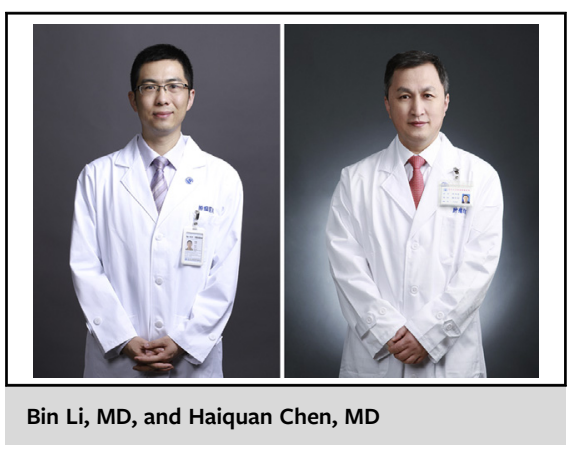

CENTRAL MESSAGE

The optimal anastomosis technique for esophagectomy is the subject of debate, but surgeons always have their preference.

included 2-layer and 3-layer techniques, and stapled anastomosis included end-to-side and side-to-side techniques. However, the cervical anastomotic leakage is still a common issue in published reports. It is unfortunate that there is still no consensus on the optimal surgery protocol for cervical anastomosis, as elucidated by Järvinen and colleagues. $^{2}$

However, stapled technique is widely used for thoracic anastomosis. In our trial comparing 3-field versus 2-field lymphadenectomy, all 400 patients underwent thoracic stapled anastomosis via right thoracic approach, with the incidence of thoracic leakage of $3.5 \%$ (14 out of 400$).{ }^{3}$ In our previous trial comparing esophagectomy via left and thoracic approach, the incidence of thoracic leakage via left thoracic approach and right thoracic approach were $5.3 \%$ ( 8 out of 150 ) and $1.3 \%$ ( 2 out of 150 ), respectively. ${ }^{4}$ Thus, based on the data, there is no doubt that the stapled technique is the better option for thoracic anastomosis.

Among the most complex surgeries, esophagectomy can be performed via different approaches in different hospitals, including open, minimally invasive, and robotics-assisted approaches. Each approach needs a long learning curve with learning-associated morbidity. The learning could be more efficient in hospitals with higher annual volume, which justified the centralization of this surgery to highvolume hospitals in recent years. In a population-based study, higher annual and cumulative surgeon volume independently influenced the prognosis after esophagectomy. Due to different training, a surgeon's preference and surgeon volume can be specific. Thus, for cervical anastomotic leakage, we probably never know which is better between 
hand-sewn and stapled technique, but surgeons always know which is the better for themselves.

\section{References}

1. Biere SS, Maas KW, Cuesta MA, van der Peet DL. Cervical or thoracic anastomosis after esophagectomy for cancer: a systematic review and meta-analysis. Dig Surg. 2011;28:29-35.

2. Järvinen T, Cools-Lartigue J, Robinson E, Räsänen J, Ilonen I. Hand-sewn versus stapled anastomoses for esophagectomy: we will probably never know which is better. J Thorac Cardiovasc Surg Open. 2021;7:338-52.
3. Li B, Hu H, Zhang Y, Zhang J, Miao L, Ma L, et al. Three-field versus two-field lymphadenectomy in transthoracic oesophagectomy for oesophageal squamous cell carcinoma: short-term outcomes of a randomized clinical trial. Br J Surg. 2020;107:647-54.

4. Li B, Xiang J, Zhang Y, Li H, Zhang J, Sun Y, et al. Comparison of Ivor-Lewis vs Sweet esophagectomy for esophageal squamous cell carcinoma: a randomized clinical trial. JAMA Surg. 2015;150:292-8.

5. Derogar M, Sadr-Azodi O, Johar A, Lagergren P, Lagergren J Hospital and surgeon volume in relation to survival after esophageal cancer surgery in a population-based study. J Clin Oncol. 2013;31: 551-7. 